\title{
Urban Green Space: Comparing the EU and Ukrainian Practice
}

\author{
Ihor Lishchynskyy ${ }^{1 *}$, Mariia Lyzun ${ }^{1}$, Evangelos Siskos $^{2}$, Yevhen Savelyev ${ }^{1}$ and Vitalina Kuryliak ${ }^{1}$ \\ ${ }^{1}$ West Ukrainian National University, 46009 Ternopil, Ukraine \\ ${ }^{2}$ University of Western Macedonia, 52100 Kastoria, Greece
}

\begin{abstract}
The goal of the paper is to compare the urban green space practice in the EU and Ukraine to find the advantages and drawbacks of both approaches. In order to reach the goal, following tasks has been raised: (1) to reveal the most common patterns of green space allocation in European cities; (2) to consider the urban green landscape in Ukrainian first-tier and second-tier cities; (3) to compare the trends and challenges of urban green space allocation in the EU and Ukraine. In Europe, a typical pattern of green space is a combination of greenbelts, regional green areas, green wedges, green middles, green infrastructure, etc. The main significant feature and advantage of green areas in European cities is the connectivity of the larger objects (parks and woods) and smaller ones (squares, boulevards, inter-quarter plantings, etc.). Urban territories in Ukraine involves quite large green areas (mostly by combining "communal parks" and "green infrastructure"). Transformation crisis leads to the vast decline of industrial zones, which were spontaneously transformed into de-facto green or brown spaces. After economic recovery green space is shrinking dramatically under the pressure of commercial and residential zones. For Ukraine, the challenge is the creation of small urban landscaping facilities and increasing functional content and quality of the existing green spaces.
\end{abstract}

\section{Introduction}

The pattern for spreading of cities in the outer green landscape has been an issue for more than a century. Depending on the design of the urban structure, green space could be considered both as the separating element between city and suburbia, and as the connecting link between people/districts/cities.

In terms of urban subject green space is rather diverse and could be classified from the perspectives of its size, purpose, vegetation cover, proximity to public transport and other facilities, etc [1,2].

Public green space includes:

- parks, sporting fields, community gardens, reserves and nature conservation areas;

- greenways and trails, street trees, stream and riverbanks;

- other less conventional spaces such as green walls, cemeteries, green alleyways.

Private green space incudes:

- household backyards and communal grounds of apartment buildings;

- corporate campuses [3, 4].

However, the combination and spatial placement of the green areas varies depending from national traditions and geographical conditions of the city.

The goal of the paper is to compare the urban green space practice in the EU and Ukraine to find the advantages and drawbacks of both approaches. In order to reach the goal, following tasks has been raised: (1) to reveal the most common patterns of green space allocation in European cities; (2) to consider the urban green landscape in Ukrainian first-tier and second-tier cities; (3) to compare the trends and challenges of urban green space allocation in the EU and Ukraine.

\section{Theoretical review of green space impact}

There is a general consensus among the society that urban green space provides the ecological integrity of cities and has a positive effect on public health. Among the main proved advantages are:

- reduction of air pollution by absorbing certain airborne pollutants from the atmosphere [5];

- temperature moderation by providing shade and cooling an area [6];

- noise attenuation;

- groundwater replenishing [7].

Numerous investigations focused on linkages between green space and health or mortality [8-9]. There is a strong correlation between parks availability and local physical activity and respective health enhancement [10]. Parks and the obesity epidemic is also revealed [11]. Besides green space is associated with psychological well-being [12] and stress reduction [13].

However, some disadvantages should be also mentioned, including threats to vulnerable persons with allergies, the concentration of criminals and socially excluded persons, high costs of maintenance, etc. Besides some researches show that the irrigation, fertilizer, mowing and leaf blowing all add up, emitting more carbon dioxide and other greenhouse gases than the spaces absorb [14]. Sometimes park-adjacent neighbourhoods (especially in low-income communities) have higher pollution concentration [15]. Nevertheless,

\footnotetext{
* Corresponding author: lischynigor@,ukr.net
} 
the abovementioned positive effects overwhelm these disadvantages.

The researchers highlight that green space is often uniquely distributed among society members. Access to green space could be stratified based on income, age, gender, (dis)ability, etc. Such a phenomenon is known as environmental injustice that is a subject of numerous recent investigations $[16,17]$.

Usually, low-income people reside in the urban core or inner-ring suburbs where areas are insufficiently landscaped or poorly maintained. More affluent residents live in areas of the suburban periphery with lots of greenery. Such areas are well-serviced and wellmaintained [18].

This environmental injustice has been taken into account in urban planning, which has led to the implementation of park development programs and various strategies for landscaping poor areas. But increasing additional greenery in these areas can create an urban green space paradox. Due to the rise of green space, which is well-serviced and well-maintained, the attractiveness of these areas as well as the costs of housing are growing. The housing cost increasing can potentially lead to gentrification: the exclusion or displacement of the residents for whom the landscaping was carried out [19].

\section{Green space pattern}

Constant urban growth resulted in numerous environmental problems connected with air, water and noise pollution. Uncontrolled city expansion and chaotic blending of urban and rural areas lead also to the lack of adequate city infrastructure in the suburbs and respective traffic growth toward infrastructure-abundant districts. To bring control over the urban growth, different patterns of green space location are applied in the practice of city planning.

In Europe, the options of the common urban green landscape can be conditionally placed on a kind of scale between the two extreme scenarios:

- "greenbelts" (sometimes called "green belts"), which are aimed at curbing the spread of cities to the surrounding rural area;

- "green zones" / "green infrastructure", the task of which is to organize the urban space for its further development and expansion.

On other continents traditional urban green space pattern could be different. For instance, in East Asia historically the localities of urban and rural natures were situated next to each other. In such a case, the farms and wooded landscape provide the functions of visual amenity and cultural services even under the conditions of modern megapolises [20].

However, following the aim of the paper, we would emphasize more the Western type of urban green planning that is more typical to Ukrainian cities.

\subsection{Greenbelts}

Greenbelt mode of city planning became popular in Europe as a replacement of Medieval walls which were broken in most of the cities in the $18^{\text {th }}-19^{\text {th }}$ century [21]. The idea of greenbelt arises in popular Howard model of Garden Cities [22]. According to E. Howard, Garden Cities horizontal spreading should be strictly limited by surrounded Greenbelt - a space for agriculture and recreation.

The greenbelt concept is typically associated with the UK policy of post-World War II urban development known as "New Towns". During several waves of its implementation, new settlements have been created aiming population density reduction, first in London and Glasgow, and later in Liverpool, Birmingham, Manchester and other metropolises. Instead of the traditional peripheral extension of the urban zone along transport routes, new settlements were formed at a distance of about $50 \mathrm{~km}$. from the megapolises. They were initially completely provided with infrastructure and housing and separated from the megapolises with a vast greenbelt (Fig. 1). In general, the success of New Town's policy is linked not so much to the ban on metropolitan expansion as to the more general trends towards decentralization and deconcentration that have coincided over time with this program. After the 2000s new towns within the UK program are being created under the principles of ecopolises.

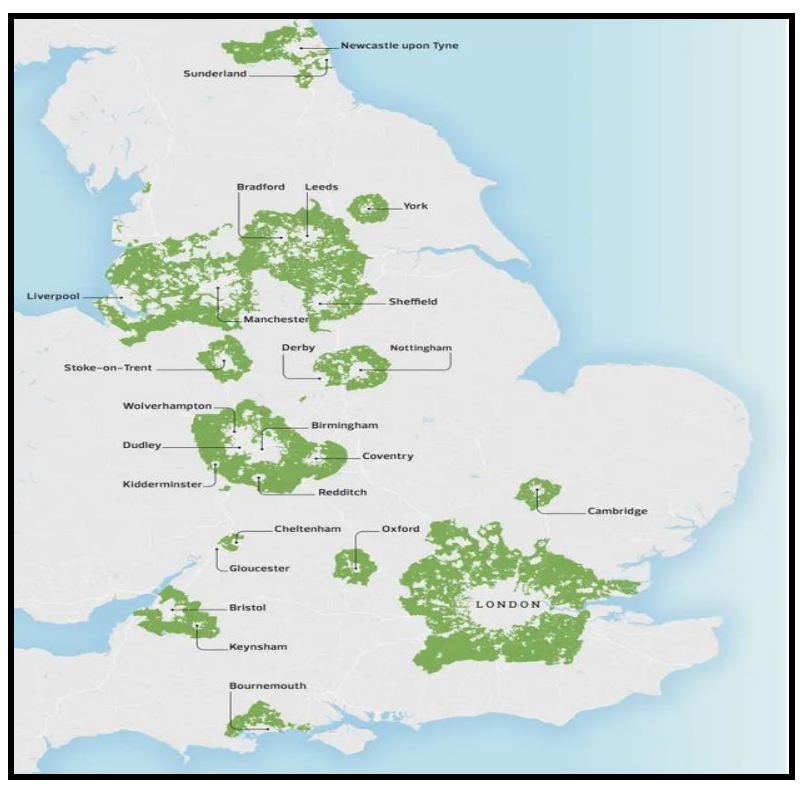

Fig. 1. Greenbelts in Great Britain (Source: theguardian.com).

The greenbelt approach was also used for some cities in France, Spain, Austria, Hungary.

Initially, the main role of greenbelt was considered in the field of controlling the urban growth, preventing conurbations (merge of agglomeration), separating of urban and rural functions. More recent arguments supporting the greenbelts are nature conservation and the issue of brownfield space [21]. 


\subsection{Regional Parks and Green Wedges}

The greenbelt approach has some long-standing disadvantages that make the city planners to look for the alternatives. Among the key drawbacks of greenbelts:

- rise of inequality between inhabitants of the area within greenbelt and outer residents;

- lack of accessibility for the general public or lack of scenical attractiveness;

- constrain of urban growth rises the average property prices and limits economic development;

- increasing the commuting distance for the residents beyond the greenbelt outer edges;

- decreasing the quality of the inner urban edges of the greenbelts due to the lack of land management.

To avoid the greenbelt drawbacks mentioned above a couple of solutions are possible. The first alternative is to "break" the circle of greenbelt to allow the controlled city overflows in the selected vectors, which are initially provided with appropriate commuting infrastructure for the residents outside the primal city ring.

A good example of such "breached" greenbelt is a system of Regional Parks around Berlin (Fig. 2). However, it should be noted that mentioned Regional Parks are not classical public parks or nature reserves. Being of a rather big size (144-964 $\left.\mathrm{km}^{2}\right)$, they are perceived rather as a rural countryside. A review of the origin and structure of Regional Parks, as well as their comparison with classical greenbelts is provided by Kühn [21].

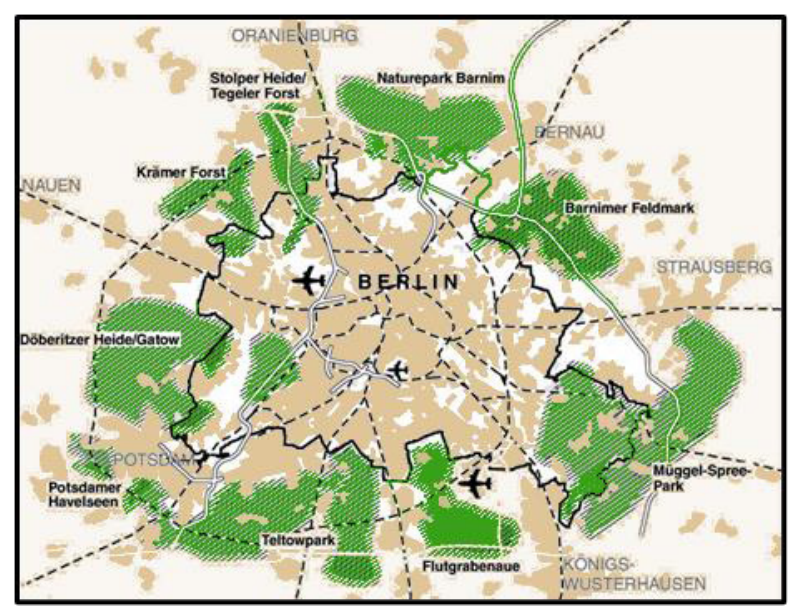

Fig. 2. Regional Parks in Berlin [21].

The second alternative to greenbelts is well described by Lindley under the name "green wedges" [23], which are specific green districts separating urban territories (Fig. 3). In the contrast to greenbelts, green wedges ensure continuing proximity of green space to the neighbourhood urban districts, providing the area for recreation, sport, education, air quality and water management, green commuting, nature conservation etc. An important feature of green wedges is their ability to be expanded alongside urban growth corridors, providing the sustainability of green space and lowering the real estate price pressure.

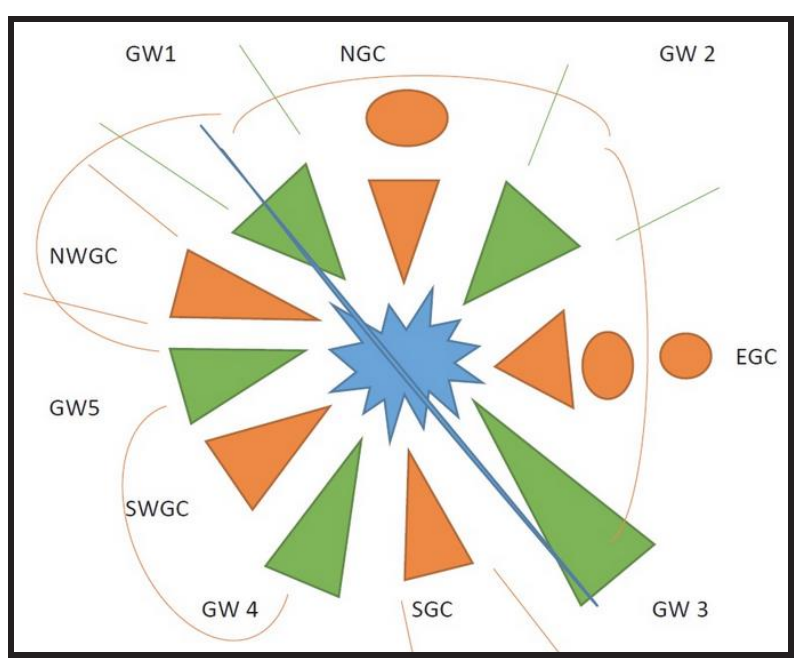

Fig. 3. Green wedges (GW) and growth corridors (GC) scheme [23].

The examples of green wedges implementation are "Finger Plan" developed for the post-WW II Copenhagen or 1988 Leicester city planning.

\subsection{Green middle}

Both previous cases were examples of green space as a stopper or separator of urban growth. However, green space could also fulfil the integrative function. Being an open space structure, it could connect different communities into a single unity.

A good example of the integrative green middle is Dutch city region Randstad - the conurbation of four major cities in the Netherlands: Amsterdam, Rotterdam, Utrecht and the Hague (Fig. 4). The Randstad is the case of the urbanized belt around the green core (the latter is known as "Green Heart").

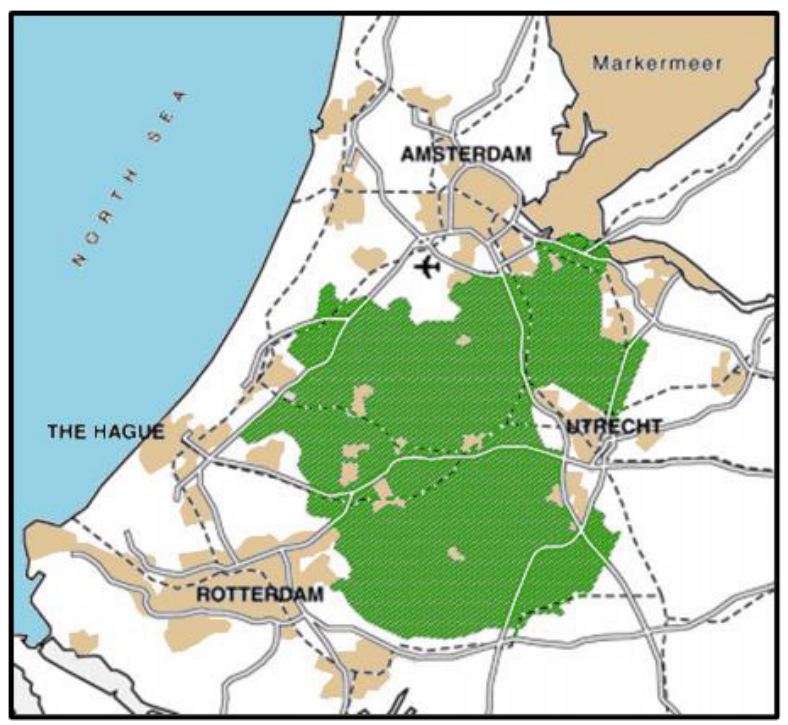

Fig. 4. Green Heart of the Randstad, the Netherlands [21]

The Green Heart is mainly the agricultural territory typically used for pastures. Its area covers around $1,500 \mathrm{~km}^{2}$ and includes 70 local municipalities (though population growth in the area was an object of indirect limitation). The share of recreation and nature 
conserving areas are rather low. Thus, Randstad is the case of a regional city limited from the expanding to the middle. While the Green Hart is simultaneously the separator and integrator of urban growth [21].

\subsection{Green infrastructure}

In the previous sections, we emphasized mainly the vast green spaces influencing general urban-rural landscape. However, there are dozens of other green space types affecting city planning. Some of them were mentioned in the Introduction.

We could distinguish among the most influencing: green corridors and green infrastructure.

The green corridors form the linear natural network that connect different city districts or green/open spaces (example of Barcelona green corridors is provided in Fig. 5).

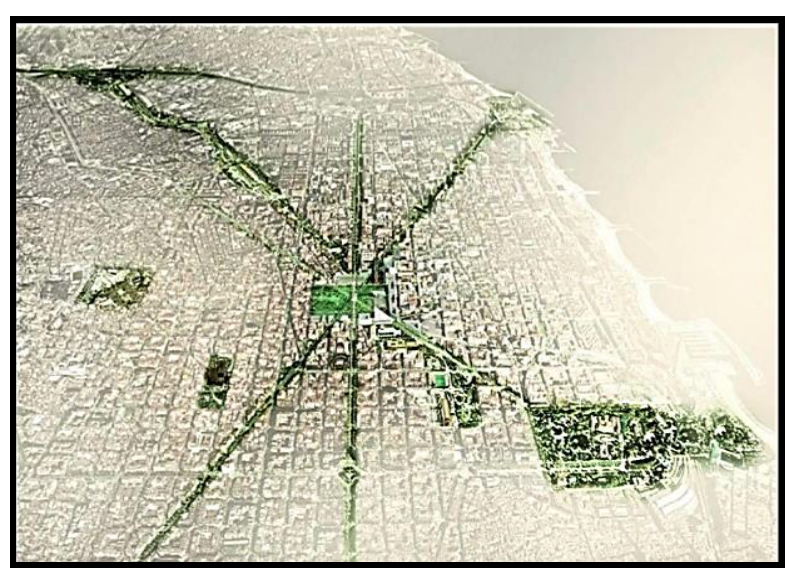

Fig. 5. Green corridors in Barcelona (Source: bloomberg.com)

Despite their relatively narrow size, green corridors can provide some functions of the larger green areas: protection from pollution and noise, enhancement of physical activity and public transport usage, increase the levels of social interactions, protection from high temperature and strong winds, provide urban biodiversity.

Green infrastructure issues are of crucial importance for the compact city planning mode. The main idea of the compact city is avoiding of classical urban zoning and provision the multifunctionality of land use to promote social cohesion and reduce motorization. Under such conditions, the minimum density of residential buildings should be 40-80 units of 2-4-storey buildings per hectare. The residential buildings are placed around the nodes, which also unite the structural elements of employment, education, commerce, recreation, etc. to maximize the share of local interaction.

However, compact city mode doesn't leave enough space for the green areas inside the city inner boundaries. Green infrastructure should be removed on the district outer fringes forming small green belts for the districts inside a city. In 2008-2014 compact city model was applied for 13 largest cities in Norway under urban revitalization strategy [24].

The case of green infrastructure is shown in the Fig. 6.

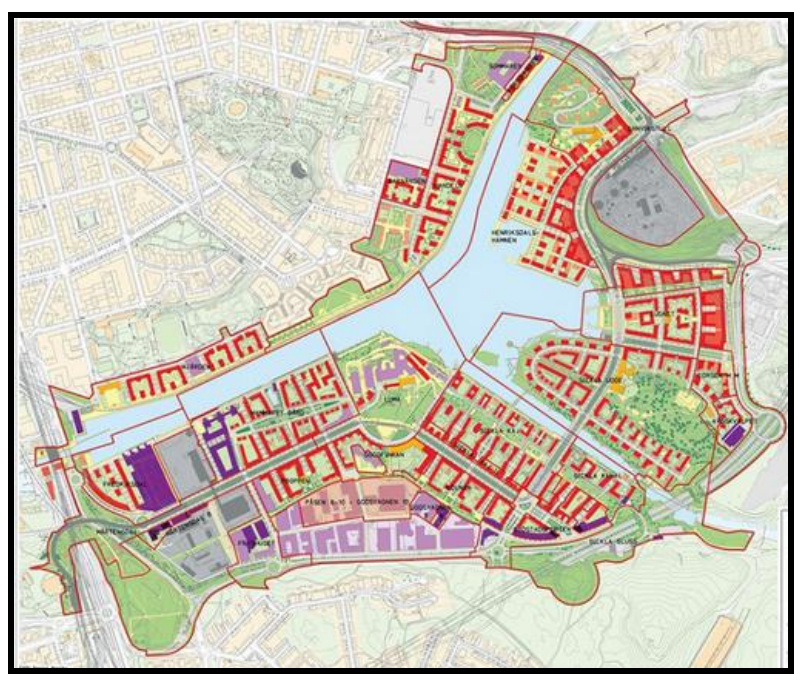

Fig. 6. Green infrastructure for the Hammarby Sjöstad district in Stockholm (Source: urbangreenbluegrids.com)

\section{Urban green space in Ukraine}

\subsection{Urbanization in Ukraine}

Urbanization is a global trend today. According to the $\mathrm{UN}$, more than half of humanity already lives in urban areas. In 2018 this figure was 55\%. Europe is considered as one of the most urbanized regions in the world, the average level of urbanization here is $74.5 \%$, while in Ukraine this rate is $69 \%$.

According to the State Statistics Service of Ukraine, at the beginning of 2019 in Ukraine, there were 461 cities (1344 urban settlements), where more than $69 \%$ of the population lived. The rate of urbanization is constantly growing despite the general depopulation. According to the State Statistics Service of Ukraine for 2015-2020, the growth rate of the urban population share was $0.35 \%$. The largest share of the urban population is observed in Donbas, Kyiv, Dnipro and Kharkiv regions (Fig. 7.1a). However, high population density is also observed near the Carpathian Mountains, due to the high population density in rural and small urban settlements (Fig. 7.1b).

In recent years, 6 cities in Ukraine have implemented metropolitan functions. The city of Kyiv $(3.0 \mathrm{mln}$ inhabitants) is part of the world metropolitan network, the cities of Kharkiv (1.4 mln), Odesa (1.0 mln), Dnipro $(1.0 \mathrm{mln})$, Lviv $(0.8 \mathrm{mln})$ are regional metropolises of Ukrainian level. Donetsk has de-facto lost such function nowadays due to the occupation.

There are numerous typologies of cities with their limitations. In the paper we explore the concept of firsttier (capitals) and second-tier cities. We define the second-tier cities according to the methodology of ESPON/SGPTD 2012 Report as “... those cities outside the capital whose economic and social performance is sufficiently important to affect the potential performance of the national economy". Thus, all abovementioned cities accept Kyiv we would consider as second-tier cities. 
Simultaneously with the processes of population concentration in metropolitan agglomerations caused by migration, there is a significant decrease in the population of cities beyond first- and second-tier. The exception is satellite cities that form pendulum migration channels with their first-tier and second-tier vis-à-vis. Almost half a million people come to Kyiv every day from the outside region, which is about $30 \%$ of the latter's population. In turn, satellite cities are becoming centres of gravity for the rural population due to relatively cheap housing for permanent residence (compared to the centre of the agglomeration) and reasonable transport links. Rural peripheral settlements in most cases are experiencing accelerated socioeconomic degradation. At the same time, rural settlements located at short distances from the $1^{\text {st }}$ and $2^{\text {nd }}$ tier cities are migratory stable or increase their population.

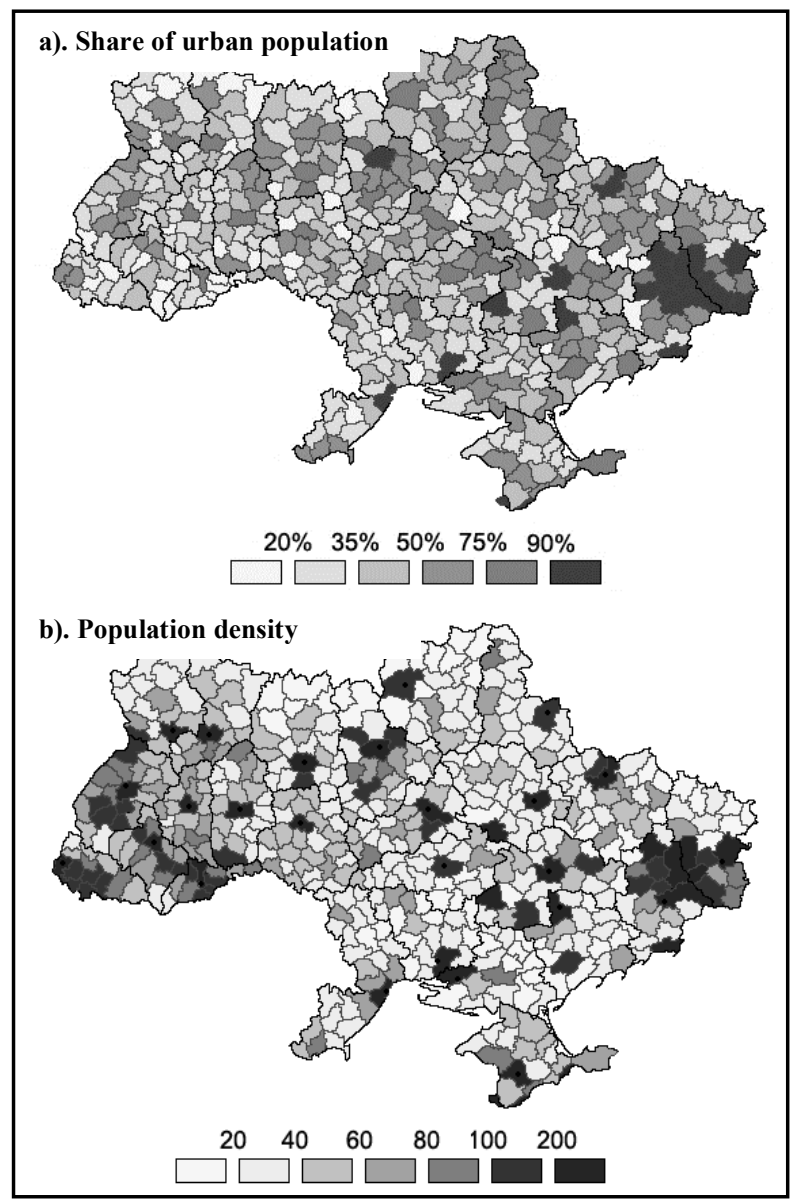

Fig. 7. Urbanization and population density in Ukraine (a year before Crimea and Donbas annexation) [25] (Source: ukrstat.gov.ua)

Besides, there is a clear pattern: the level of poverty increases with decreasing settlement size, and if small cities are close to rural areas in terms of poverty, then large ones, especially Kyiv, are sharply contrasted to small settlements. Thus, the poverty rate (according to the relative criterion of $75 \%$ of the median equivalent expenditure) in Kyiv is $14.1 \%$, in other large cities $17.8 \%$, in small cities $-26.6 \%$, in villages $-30.8 \%$. Accordingly, a significant number of residents of villages and small towns migrate (want to migrate) to large cities to improve their financial situation. The above mentioned is making significant pressure on urban resident zones, which in their terms became a threat to the urban green scale.

\subsection{Cases of green space in Ukrainian cities}

Typical city pattern in Ukraine of the Soviet era has been of classical urban zoning type with clear central, industrial, and residential (so-called "sleeping") zones. Green space (communal park or preserved wooded area) in such a structure has often had the form of a specific zone that separates the districts of other types. Such structure is still observed in most first-tier and secondtier cities (see Fig. 8 for Ukrainian second-tier cities).

For instance, the green areas of Kharkiv cover an area of 15.4 thousand hectares. The indicator of the greenness of the city makes 50,4 per cent at the norm of 45 per cent $\left(13.3 \mathrm{~m}^{2}\right.$ of green space per capita at the norm of $13 \mathrm{~m}^{2}$ ). However, of these, only 7.5 thousand hectares are green areas for public use (parks, forests, meadows, water parks, gardens, squares, boulevards). The largest areas occupied by greenery are located along the western and northern borders of the city, going "wedges" deep into the built-up areas. The insufficient number of green areas are in the northeast, east, and southeast of the city, where most industrial zones are located. This negatively affects the sanitary and ecological conditions of residential districts in the neighbourhood. In general, the area of the green zone of Kharkiv is relatively sufficient. However, the bulk of green space is concentrated on the outskirts of the city. This indicates that, despite the high rate of green space, most of the city is inadequately provided with green spaces of a small type.

The geographical location of Odesa by the sea has led to the formation of a green space, which is not typical for other cities in Ukraine. The most vital in the urban landscape is the coastal park area (30 km length). This green area is of crucial importance for the general resort zone in the summer months, during the arrival of hundreds of thousands of vacationers. Besides, in every residential area of the city, there are parks, squares, boulevards. During the last decades due to the lack of vacant land within the city, the agricultural lands were allocated for construction. Often green space in these residential areas was not designed and created. The most significant factor limiting the increase in the efficiency of green plantations is the insufficient area of public green space. According to the General Development Plan of Odesa, the territory of green space in the city covers 5.4 thousand hectares, of which 1.0 thousand are for public use. Thus, the area of greenery is only 17 per cent of the city. In some city districts per capita indicator is lower than $20 \%$ of the national norm [26].

Lviv is one of the greenest cities in Ukraine $\left(54 \mathrm{~m}^{2}\right.$ of green space per capita). Moreover, most of the green territory is situated within city borders. Due to the complicated relief of the city, the residential area doesn't threaten relatively the green zone. The historical centre of a city is surrounded by the first green ring that is 
rather wide. Besides, there are two other rings formed by parks and nature preserved areas. Among the disadvantages is the quality of some parks that are not adapted properly to the recreation function.

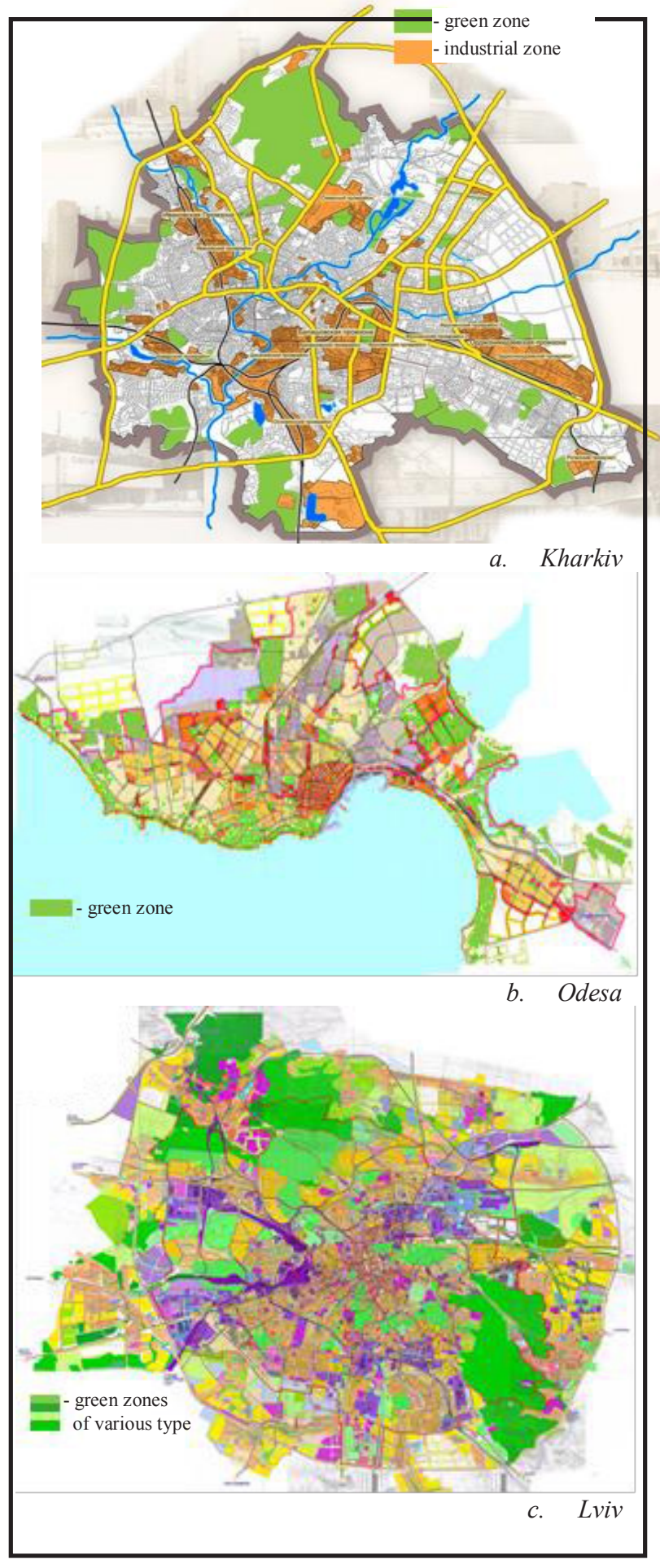

Fig. 8. Green (wooded) spaces in Ukrainian second-tier cities (Source: cities' General Plans)

On the other hand, the green pattern of Kyiv, the capital of Ukraine, is marked by a classical green wedge structure with powerful blue axe formed by Dnieper river (Fig. 9). In spite of constant growth of the metropolitan population, the latest revisions of the city General Plan doesn't prescribe the horizontal growth of residental zone. Though there are cases of hidden or semi-official transfer of green territory to fulfil the commercial and residential functions.

The type of green landscape is varied depending on the regions of Ukraine. Due to the climate, Northern and Western cities are more provided with wooden areas. While the outskirts of the Southern and Eastern cities are mainly cultivated plains with rare forests or bushes beside the roads.

In general, urban territories in Ukraine involves quite large green areas (mostly by combining "communal parks" and "green infrastructure"). Besides deindustrialization of the 1990s leads to the vast decline of industrial zones, which were spontaneously transformed into de-facto green or brown spaces of postindustrial character (abandoned buildings, a lot of garbage around). This process often closes the circles of greenbelts around a lot of 2-nd and 3-rd tier cities.

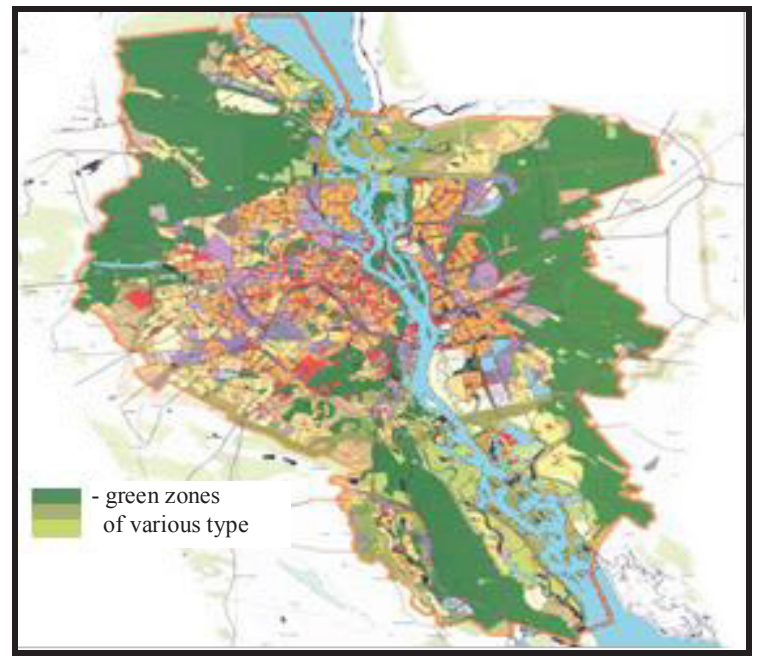

Fig. 9. Green (wooded) spaces in Kyiv (Source: city’s General Plan)

The economic recovery of the 2000s reversed the tendency. Green space is shrinking dramatically under the pressure of commercial and residential (the corruption element is very high in the sphere of issuing the permits for activity in nature preserved areas). The suburban residential zones in a $15 \mathrm{~km}$ radius around the regional centres expand rapidly making additional pressure on the outer fringes of greenbelts.

Liberalization of automobile import taxation in 2014 increases the number of cars owned. City transport arteries in a lot of older cities are no longer able to maintain the traffic. To expand the roads green infrastructure is often removed. A typical related issue is a lack of space for the green landscape because of the redundant dwelling or commercial buildings. This problem requires alternative solutions or radical rearranging of city plans. However, the latter is often impossible due to the scarcity of city budgets.

\section{Conclusions}

Comparing the landscaping of European and Ukrainian cities, we see rather different approaches. In Europe, the typical pattern of green space is a combination of ring- 
radial, linear, wedge-shaped, spotted landscaping, etc. The main significant feature and advantage of green areas in European cities is the connectivity of the larger objects (parks and woods) and smaller ones (squares, boulevards, inter-quarter plantings, etc.). This allows forming a virtually indivisible ecosystem of the city green zone. The joint fragmentation of the green space is a surprisingly important characteristic, as it increases its resistance to external influences, and multiply the advantages of green territory.

Green space volume in Ukraine is not smaller than those in the EU. However, the indicator of green area per capita is not very relevant in our subject. More important is the quality of these landscapes. Given the scarcity of territory, which is an urgent problem in urban cities both in the EU and Ukraine, the special attention of city planners is paid to the more efficient use of the existing green areas. For Ukraine, the challenge is the creation of small urban landscaping facilities and increasing their functional content. Specialists in green space planning should pay attention to the wider introduction of such a widely used in Europe method as vertical landscaping, especially for its central part, where dense low-rise buildings predominate.

According to the national practice, the wooded area is considered mainly as a green space in Ukraine. Thus, European experience of green zone definition could be also applicable for better fulfilment of urban functions.

\section{Acknowledgements}

This work was supported by the Erasmus+ program of the European Union (Jean Monnet Module 612067-EPP1-UA-EPPJMO-MODULE "European Regional Policy: Balance of Local, National and Pan-European Interests"). The European Commission support for the publication of this article does not constitute an endorsement of the contents, which reflects the views of the authors only, and the Commission cannot be held responsible for any use, which may be made of the information contained therein.

\section{References}

1. N. Dahmann, J. Wolch, P. Joassart-Marcelli, K. Reynolds, M. Jerrett, Health Place 16(3), 431445 (2010)

2. C. Sister, J. Wolch, J. Wilson, GeoJournal 75(3), 229-248 (2010)

3. J. R. Wolch, J. Byrne, J. P. Newell, Landsc. Urban Plan. 125, 234-244 (2014)

4. S. Roy, J. Byrne, C. Pickering, Urban for Urban Green 4(11), 351-363 (2012)

5. D. J. Nowak, D. E. Crane, J. C. Stevens, Urban for Urban Green 4, 115-123 (2006)

6. S. K. Cummins, R. J. Jackson, Pediatr. Clin. N. Am. 48(5), 1241-1252 (2001)

7. F. J. Escobedo, T. Kroeger, J. E. Wagner, Environ. Pollut. 159(8), 2078-2087 (2011)
8. A. M. Dzhambov, M. H. Browning, I. Markevych, T. Hartig, P. Lercher, Environ. Res. 186, 109613 (2020)

9. C. Coutts, M. Horner, T. Chapin, Geocarto Int. 25(6), 471-484 (2010)

10. J. F. Sallis, M. F. Floyd, D. Rodriguez, B. E. Saelens, Circulation 125, 729-737 (2012)

11. C. L. Ogden, M. D. Carroll, K. M. Flegal, JAMA 299(20), 2401-2405 (2008)

12. H. Ernstson, Landsc. Urban Plan. 109(1), 7-17 (2012)

13. J. Woo, N. Tang, E. Suen, J. Leung, M. Wong, Lancet, 373(9660), 299-300 (2009)

14. A. Townsend-Small, C. I. Czimczik, Geophys. Res. Lett. 37(2) (2010)

15. J. Byrne, Geoforum 43(3), 595-611 (2012)

16. R. Bick, E. Halsey, C. C. Ekenga, Environ. Health 17(1), 1-4 (2018)

17. J. E. Givens, X. Huang, A. K. Jorgenson, Sociol. Compass 13(5), 12693 (2019)

18. N. Heynen, H. A. Perkins, P. Roy, Urban Aff. Rev. 42(1), 3-25 (2006)

19. R. Bentley, E. Baker, K. Mason, J Epidemiol Community Health 66, 761-766 (2012)

20. M. Yokohari, K. Takeuchi, T. Watanabe, S. Yokota, Landsc. Urban Plan. 47, 159-171 (2000)

21. M Kühn, Landsc. Urban Plan. 64, 19-27 (2003)

22. E. Howard, Garden Cities of Tomorrow (Faber \& Faber, London, 1946).

23. I. Lindley, Green belt vs. Green wedge (Landscape Institute, 2019, URL:

https://www.landscapeinstitute.org/blog/green-beltvs-green-wedge/)

24. H. Hofstad, Eur. J. Spat. Dev. 49, 1-23 (2012)

25. I. Lishchynskyy, Poliusy ta osi rozvytku v konteksti glokalizatsiinykh procesiv (TNEU, Ternopil, 2019)

26. I. Sholok, Bulletin of KhNU named after V. Karazin 1140 (2014) 